\title{
SOCIEDADE DE CONSUMO E A (IN)SUSTENTABILIDADE DO SISTEMA CAPITALISTA VIGENTE
}

http://dx.doi.org/10.21527/2176-6622.2021.56.12633

Recebido em: 15/8/2021

Aceito em: 26/8/2021

Daniel Rubens Cenci

Autor correspondente. Universidade Regional do Noroeste do Estado do Rio Grande do Sul - Unijuí. Rua do Comércio, 3000 - Bairro Universitário. ljuí/RS, Brasil. CEP 98700-000. http://lattes.cnpq.br/2325516905314833. https://orcid.org/0000-0001-7919-6840. danielr@unijui.edu.br

Willian Matheus Heineck Universidade Regional do Noroeste do Estado do Rio Grande do Sul - Unijuí. ljuí/RS, Brasil.

\section{RESUMO}

O presente trabalho aborda a relação entre homem e natureza na perspectiva existencial, qual seja, a dependência do ser humano no que diz respeito a sua vida e bem-estar, diante da necessidade de consumir. Tal prática causa uma gama de consequências que podem comprometer a própria existência humana na Terra. O objetivo é analisar os impactos causados pela escolha consumista de vida e a organização capitalista da economia, sua condição insustentável perante a crise ambiental cotidiana. Em termos metodológicos, trata-se de uma pesquisa qualitativa, uma vez que se busca apresentar formas de (re)interpretar a sociedade de consumo e a construção de saberes outros, para uma sociedade sustentável, voltada para o respeito à natureza e a todas as formas de vida, superando o modelo capitalista de produção e consumo vigente.

Palavras-chave: Biodiversidade; consumo; crise ambiental; sociedade sustentável.

\section{CONSUMER SOCIETY AND (UN)SUSTAINABILITY OF THE CURRENT CAPITALIST SYSTEM}

\section{ABSTRACT}

This paper addresses the relationship between man and nature from an existential perspective, that is, the dependence of human beings with regard to their life and well-being, in view of the need to consume. Such practice causes a range of consequences that can compromise human existence on Earth. The objective is to analyze the impacts caused by the consumer choice of life and the capitalist organization of the economy, its unsustainable condition facing the daily environmental crisis. In methodological terms, this is a qualitative research, as it seeks to present ways to (re)interpret the consumer society and the construction of other knowledge, for a sustainable society, focused on respect for nature and all ways of life, surpassing the current capitalist model of production and consumption.

Keywords: Biodiversity; consumption; environmental crisis; sustainable society. 


\section{INTRODUÇÃO}

Uma das piores consequências do modo de vida consumista que o ser humano vive na atualidade ocasiona a constante destruição dos recursos naturais que o planeta oferece. A ilimitada produção de bens materiais utilizados como matéria-prima, extraída do planeta Terra, prática induzida pelo sistema capitalista consumista, não dá conta da satisfação das infinitas necessidades que o homem cria para si próprio, o que está tornando o capitalismo um modelo insustentável ambientalmente. Isto significa que, ao prosseguir com o processo de esgotamento de recursos vigente, em breve os recursos naturais oferecidos cessarão e as consequências ambientais da exploração do planeta tornarão a vida do ser humano na Terra extremamente difícil, quando não impossível.

O grande paradoxo deste modelo manifesta-se na pretensão de atender às necessidades a qualquer custo, causando profundos impactos na natureza, mas o homem pode perceber seu vínculo de sobrevivência com a natureza e passar a preservá-la. Para isto acontecer, porém, é preciso entender que esta necessidade já existe e que as condições de vida do homem no planeta Terra estão cada vez mais ameaçadas.

O drama do atual contexto é que a principal fonte propulsora para o modo de vida consumista do capitalismo centra-se na exploração do planeta, ou seja, o principal responsável pelo possível comprometimento da qualidade de vida humana, assim como a conhecemos, é o próprio ser humano. O homem consumista, que assim é, pois busca realizar sua felicidade no consumo de bens materiais, precisa perceber que ao criar tantas necessidades, produziu a conveniência de não as criar mais. Para entender melhor esta crise e a equação resultante, busca-se aqui analisar os efeitos do modo de vida consumista no planeta Terra.

O desenvolvimento como atualmente concebido e as consequências do crescimento do capitalismo estão tornando-se insustentáveis ambientalmente. E é este ponto de insustentabilidade do modelo que será melhor discutido neste artigo. A confrontação com a perspectiva de geração de bem-estar com elevação infinita dos índices de consumo não são apenas paradoxo com a capacidade do planeta Terra na oferta de bem, mas interdita a capacidade existencial da vida humana.

\section{CAPITALISMO E (IN)SUSTENTABILIDADE}

Vive-se um momento da história de nosso planeta no qual a discussão sobre o desenvolvimento agregou uma dimensão qualificadora do contexto. Desenvolvimento sustentável tem representado o novo conteúdo, tendo aumentado e ganhado espaço, tanto entre os governos dos países como nas universidades, empresas, fóruns, congressos e redes sociais em geral. Os diversos estudos existentes e os próprios fatos do cotidiano, como as catástrofes climáticas, por exemplo, já comprovaram de todas as formas que o meio ambiente vem sofrendo mudanças drásticas em sua estrutura e interações, impactando negativamente a qualidade de vida humana, a biodiversidade e o conjunto de elementos que dão suporte à vida, promovendo a emergência do debate referente ao desenvolvimento com sustentabilidade. O maior motivo disso? A constante exploração da natureza, sem medidas ou cuidados que busquem manter um mínimo de sua saúde e equilíbrio.

O descaso com a vida do planeta é identificado em inúmeras áreas hoje comprometidas, como qualidade dos solos, das águas, do ar, na extinção de espécies, manifestos nos índices de exploração e extrativismo, gerando déficit na capacidade do planeta no que respeita à oferta de bens naturais, o que deveria oferecer perspectivas e abrigar infinitas gerações, já se apresenta insustentável e ocupa o centro das discussões, visto que tamanha indiferença poderá encurtar a existência do ser humano no planeta. Conforme assevera Jamieson, "muitos biólogos acreditam que a sexta maior onda de extinção desde o princípio da Terra está ocorrendo agora, e que esta, diferentemente das outras cinco, está sendo causada pela ação humana" (JAMIESON, 2010, p. 24). O que falta entender é que o planeta Terra não vai acabar, mas as ações do homem vão levá-lo a um novo ciclo, uma nova era. Está acabando, na verdade, o tempo de vida do próprio ser humano presente nele. Esta será a grande consequência dos seus atos.

Mas não nos iludamos. Nós, seres humanos, não temos nenhuma chance de ganhar esta guerra irracional e desapiedada, pois a Terra é ilimitadamente mais poderosa que nós. De mais a mais, nós precisamos dela para viver. Ela não precisa de nós. Existiu bem antes do ser humano e pode, tranquilamente, continuar sem a nossa 
presença. Mas será uma perda inimaginável para o próprio universo que, nesta sua pequena porção que é o nosso planeta, nada mais se poderá, mediante o ser humano inteligente e consciente, ver-se a si mesmo e contemplar a sua majestade (BOFF, 2012, p. 23).

Um dos principais motivos desta exploração ambiental tão prejudicial ao planeta é o sistema econômico irracional, adotado em quase todo o mundo, o modelo capitalista, no qual nada é mais importante que o ganhar mais, acumular, render mais, enriquecer mais. Assim como o próprio ser humano foi transformando-se em um mero indivíduo que deve trabalhar para poder consumir, o meio ambiente tornou-se a vítima de toda e qualquer exploração que possa ser rentável aos detentores do poder econômico e da propriedade privada. Vive-se um período de ruptura com a mãe Terra, convertida em terra commodity.

Tal sistema passa por cima de tudo e de todos para manter-se vigoroso, sobreviver às próprias crises e renovar-se ou reinventar-se, conforme sua necessidade, sempre priorizando a lucratividade. Dessa forma, o ambiente natural e suas riquezas têm sido uma das principais vítimas, uma vez que nele está presente toda a matéria-prima necessária para a produção, a base do extrativismo que mantém o sistema em funcionamento. Boff demonstra isto com clareza, alertando que é preciso mudar este paradigma caso se queira andar minimamente no rumo da sustentabilidade.

O gênio do sistema capitalista se caracteriza por sua enorme capacidade de encontrar soluções para suas crises, geralmente promovendo a destruição criativa. Ganha destruindo um sistema e ao reconstruí-lo. Mas desta vez ele encontrou um obstáculo intransponível: os limites do planeta Terra e a escassez crescente de bens e serviços naturais. Ou encontramos outra forma de produzir e assegurar a subsistência da vida humana e da comunidade de vida (animais, florestas e os demais seres orgânicos) ou então poderemos conhecer um fenomenal fracasso que traz em seu bojo grave catástrofe social e ambiental (BOFF, 2012, p. 19).

Percebe-se que em momento algum da História o ambiente, a natureza ou sua continuidade foram considerados. O modelo econômico foi pensado e analisado de maneira individualista/egoísta e antropocêntrica, buscando apenas o bem-estar das pessoas. Mesmo as visões mais críticas apenas mostravam a desigualdade social entre as classes, mas raramente questionavam o comportamento extremamente antropocêntrico que o homem teve em relação à sua própria casa comum, ou ainda, tomando em termos econômicos, à sua maior fonte de riqueza, o planeta como celeiro de bens a serem extraídos.

Eis que, com o passar dos anos, o ser humano descobre o sentido e os impactos como resultado que sua exploração irracional de matérias-primas e a crise ambiental como síntese. Mudanças climáticas, desastres ecológicos e as demais "respostas" que a natureza começou a apresentar levaram o ser humano como explorador a tornar-se curioso e passa a pensar se suas práticas realmente o caracterizam como ser inteligente, superior e se está a agir corretamente. $\mathrm{O}$ atual contexto de crise, porém, é algo muito avançado em termos de consumo e deterioração do planeta Terra. O homem criou uma sociedade materialista e extrativista, fútil e extremamente consumista. Explorou e explora o planeta mergulhado neste mesmo pensamento, com o qual não controla seus próprios atos, e mesmo vendo o mal que faz a si próprio, continua a repeti-lo, como destaca Boff.

Devemos dar especial atenção à chamada Pegada ecológica da Terra, quer dizer: quanto de solo, de nutrientes, de água, de florestas[...] o planeta precisa para repor aquilo que lhe foi tirado para o consumo humano. [...] em 1961 precisávamos de apenas 63\% da Terra para atender às demandas humanas. Em 1975 já necessitávamos de $97 \%$ da Terra. Em 1980 exigíamos 100,6\% de Terra, portanto, precisamos mais de uma Terra. Em 2005 já atingíamos a cifra de $145 \%$ da Terra. Quer dizer, uma Terra e meia para estar à altura do consumo geral da humanidade. Em 2011 nos aproximamos a 170\% da Terra. [...] A seguir este ritmo, no ano de 2030 precisaremos de pelo menos três planetas Terra iguais a este que temos. [...] a Terra já entrou, há bastante tempo, no cheque especial. Encontra-se no vermelho. Ela precisa de mais de um ano e meio para repor o que nós lhe subtraímos durante um ano. Em outras palavras, a Terra não é mais sustentável (BOFF, 2012, p. 25).

O sistema capitalista é bem claro e objetivo quando leva o homem a consumir em níveis máximos. Em regra, o homem também é muito claro quando aceita esta condição, elevando tal prática a uma condição de sobrevivência e satisfação de seus desejos e realização pessoal. A noção de felicidade é constituída baseada no materialismo, no consumismo, no acúmulo de bens. O ser humano é feliz à medida que tem maiores con- 
dições de obter e consumir bens materiais. Neste sentido, está comprometido apenas com uma vida consumista, baseada na conquista de bens materiais, esquecendo valores morais e sociais, pessoais e coletivos, que deveriam constituir a verdadeira medida de seu bem-estar. Esta situação é fruto de um sistema voltado para a exploração em prol do consumo, o capitalismo.

Esta constituição material da vida rompe a relação de equilíbrio entre o homem e a natureza, faz com que o planeta se transforme em mera matéria-prima para atender aos anseios materiais e, ao ser explorado insaciavelmente, afastado de princípios de sustentabilidade, está inviabilizando a continuidade da vida do homem nele. Seguindo este rumo de análise, a Terra continuará a existir, em outras condições, porém o homem não encontrará condições de existência, consequência da irresponsabilidade que tem com sua própria casa. Assim, conclui-se que crise ambiental acaba sendo mais uma das péssimas consequências deste processo da vida humana, que parece caracterizar-se por uma involução moral do homem. Não é possível falar de uma crise ambiental isoladamente, muito menos justificá-la sem antes entender a crise moral e civilizatória que se externaliza na crise ambiental e caracteriza o homem como o ser que explora impiedosamente o planeta Terra. Somente um redirecionamento na maneira de viver e da redefinição do que significa bem-estar, seja ele individual ou social, é que pode impedir o encurtamento do período de vida da espécie humana e de muitas outras espécies na Terra.

Um dos caminhos a serem seguidos para uma mudança de paradigma é um ponto de vista diferente sobre a ecologia. Como sugere Capra (2014), é preciso um olhar mais profundo sobre a ecologia, no qual seres humanos e meio ambiente sejam vistos como iguais, fazendo parte de um todo, entrelaçado e com uma relação de dependência. O que se observa é um olhar antropocêntrico do mundo, por meio do qual tudo e todos devem atender às necessidades do ser humano. Este é um dos principais pontos da situação de insustentabilidade socioambiental referida até aqui.

Para Capra, uma ecologia vista superficialmente é "centralizada nos seres humanos. Para ele, os seres humanos estão acima ou fora da natureza e constituem a fonte de todos os valores" (CAPRA, 2014, p. 37). A "ecologia profunda" não isola a natureza dos objetos nem do ser humano, entendendo tudo como um corpo só, com relações de dependência. "A ecologia profunda reconhece o valor intrínseco de todos os seres vivos e concebe os seres humanos apenas como um fio particular da teia da vida." (CAPRA, 2014, p. 37). Trata-se de uma intepretação muito mais ampla da ecologia, considerando homens e meio ambiente iguais e dependentes entre si.

Fala-se de uma ética ecológica, que vê o ser humano como qualquer outro ser vivo, em condições de igualdade de importância e utilidade. Foge-se do antropocentrismo atual, buscando harmonia na convivência entre o homem e os demais seres do planeta Terra.

Enquanto o paradigma mecanicista baseia-se em valores antropocêntricos, a ecologia profunda está arraigada em valores ecocêntricos (centralizados na Terra). É uma visão de mundo que reconhece o valor inerente da vida não humana, reconhecendo também que todos os seres vivos são membros de comunidades ecológicas, conjuntamente ligadas em redes de interdependências. Quando essa percepção ecológica profunda torna-se parte de nossa percepção diária, emerge um sistema radicalmente novo de ética (CAPRA, 2014, p. 39).

Da mesma forma, Joaquin Sempere (2009) aposta no ecologismo como um dos caminhos para uma mudança de vida dos seres humanos, mudando suas necessidades, não dependendo tanto das necessidades materiais e encontrando novas maneiras de sentir e desfrutar de seu bem-estar. Um bom exemplo é a volta ao campo de pessoas que anteriormente buscaram a vida urbana. Este retorno significa um reencontro com o bem-estar do contato com a natureza e da fuga da vida agitada, rápida e consumista das cidades.

Consequente às mudanças de modo de vida dos indivíduos, fugindo do consumo excessivo de bens materiais, é uma esperança de maior sustentabilidade ambiental, visto que quando menos se consumir, menor será o impacto no ambiente e menor será a pegada de destruição a Terra.

El ecologismo ha inspirado e inspira aún una contracultura con sus correspondientes plasmaciones prácticas. No ha sido sólo un movimiento de toma de conciencia, investigación, educación y reivindicativo para evitar males ecológicos y promover alternativas. Ha empujado a muchas personas a vivir de otra manera, siendo un impulsor de cambios radicales en los sistemas de necesidades y en las formas de consumir y producir (SEMPERE, 2009, p. 220). 
A mudança de paradigma trata, portanto, de uma mudança coletiva, solidária e de total superação, mas que se torna possível devido à natureza do homem de conseguir superar suas próprias crises e se reencontrar em meio aos seus erros. Uma nova visão de mundo e de vida faz-se necessária. É esta mudança que precisa acontecer. $\mathrm{O}$ alcance do desenvolvimento sustentável para a Terra, passa pelo (re) encontro do ser humano com o seu verdadeiro "eu", que carrega dentro de si os verdadeiros valores da vida, os que trazem o seu verdadeiro desenvolvimento e a sua verdadeira felicidade, encontrando-se como integrante do planeta e não como dono dele. Esta construção de valores morais, compatíveis com um mundo de sustentabilidade é, sem dúvida alguma, a tarefa mais preciosa que hoje o homem possui e possuirá durante toda a sua existência.

\section{A SUSTENTABILIDADE COMO DESAFIO E NOVAS FRONTEIRAS PARA A REALIZAÇÃO HUMANA}

A sustentabilidade ambiental no capitalismo revela paradoxos de difícil sintonia em diferentes dimensões, mas também precisa ser analisada a fim de identificar possíveis soluções, ou seja, é preciso encontrar maneiras de viver e consumir sem destruir o planeta Terra. Caso contrário, este sistema alcançará, em sua total fragilidade, um de seus pontos fracos, a insustentabilidade diante da questão ambiental, e o próprio ser humano tornará praticamente inviável sua sobrevivência na Terra.

O modo de vida baseado no consumo hoje vigente é severamente destrutivo da natureza, gerando graves consequências, interferindo no sistema ecológico, desiquilibrando as condições ambientais, impossibilitando a existência de inúmeras espécies, apontando para um caminho em que a própria existência humana se torna ameaçada. Enrique Leff (2009) alerta sobre estas condições e sobre suas possíveis consequências, sugerindo que sejam encontradas maneiras de alcançar um desenvolvimento econômico sustentável.

A racionalidade econômica que se instaura no mundo como o núcleo duro da racionalidade da Modernidade, se expressa em um modo de produção fundado no consumo destrutivo da natureza, que vai degradando o ordenamento ecológico do planeta Terra e minando suas próprias condições de sustentabilidade. Uma vez que o capital alcançou um certo grau de desenvolvimento - de elevação na sua composição orgânica - sua reprodução ampliada requer novas fontes de acumulação que the permitem ampliar as taxas de mais-valia (LEFF, 2009, p. 27).

Este desajuste entre o consumo e os recursos naturais gera uma crise ambiental, visto que a constante agressão ao ambiente na busca de recursos para produzir e atender aos anseios do capitalismo esgota a capacidade dos sistemas naturais. Não existe consciência ambiental no consumo e enquanto há recursos, mais recursos são retirados da natureza, sem pensar se futuramente esses recursos continuarão sendo ofertados pela resiliência do planeta. $O$ modo de vida que considera apenas o desejo de consumo e bem-estar humano está na base do desequilibrio ecológico, gerando insustentabilidade do sistema capitalista no modelo atual.

Caminhamos rumo a uma escassez global, na qual não haverá recursos suficientes para atender às demandas de consumo nem condições ambientais mínimas para o bem-estar do ser humano no planeta. "A degradação ambiental manifesta-se, assim, como sintoma de uma crise na civilização marcada pelo modelo de desenvolvimento construído na modernidade, no qual o desenvolvimento da tecnologia predomina, impondo impiedosa destruição da natureza" (LEFF, 2009, p. 205). A própria produção de alimentos fica prejudicada pela degradação ambiental e para que haja um futuro para o próprio capitalismo terão de ser respeitados os limites da natureza.

Enquanto a exploração abundante dos recursos naturais não apontou uma futura escassez deles nem a enorme quantidade de poluentes produzidos e inseridos na agricultura - que alimenta a sociedade - mostrou o desequilíbrio ecológico gerado, a questão ambiental do sistema capitalista não foi debatida. Ao perceber-se, porém, este cenário de possível escassez e degradação ambiental, é preciso discutir novas formas de exploração do planeta, entendendo que a fonte de recursos - planeta Terra - precisa ser tão valorizada quanto os produtos que a partir dela são produzidos.

A crise ambiental provocou a necessidade de internalizar no processo econômico o imperativo da sustentabilidade ecológica, através de formas de aproveitamento que evitem o esgotamento dos recursos não renováveis e possibilitem a produção sustentável dos recursos bióticos. O princípio da sustentabilidade emerge, assim, no 
contexto da globalização econômica, como uma nova visão do processo civilizatório da humanidade. A crise ambiental veio questionar as bases conceituais que impulsionaram e legitimaram o crescimento econômico, negando a natureza. A sustentabilidade ecológica surge, assim, como um critério normativo na reconstrução da ordem econômica, como condição de sobrevivência humana e para se conseguir um desenvolvimento durável problematizando as próprias bases de produção (LEFF, 2009, p. 206).

Sob esta mesma análise da crise ambiental, diz-se que nos aproximamos do que seria chamada de "sexta extinção, ${ }^{1 "}$ como afirma Luiz Marques Filho (2016), devido à irracionalidade ambiental da humanidade, que imagina "que podemos sobreviver sem a biodiversidade, ou que ela é, de alguma forma, periférica" (MARQUES FILHO, 2016, p. 377). Para este autor, a sustentabilidade significa vida ou morte para a humanidade. Um futuro sustentável não deve ser pensado apenas para a biodiversidade, mas preocupado com a sobrevivência da espécie humana que depende dela.

Esta "sexta extinção" possui características que a diferenciam muito das anteriores, principalmente pelo fato de ser gerada pela capacidade destrutiva de uma de suas espécies - o ser humano - na era do capitalismo global, que desencadeia a destruição das condições de vida de todas as espécies, inclusive a própria espécie humana. Ou seja, além de eliminar as espécies dominadas, a espécie humana, vista como dominante, também acaba por se autoeliminar, pelo "desfazimento da teia de sustentação biológica que lhe permite existir, e por um curtíssimo momento cultivar a ilusão de dominá-la" (MARQUES FILHO, 2016, p. 376).

Outra característica deste processo de extinção é sua rapidez. As extinções anteriores eram medidas em escalas geológicas. A unidade de tempo que mede a escala da sexta extinção vem se abreviando. "Em 1900, ela ocorria na escala de séculos. Cinquenta anos atrás, a escala de observação mais adequada seria a década. Hoje, a unidade de mensuração do avanço da sexta extinção é o ano ou mesmo o dia." (MARQUES FILHO, 2016, p. 377). Trata-se, realmente, de um processo voraz de degradação ambiental e de futura impossibilidade de vida do ser humano na Terra.

Esta situação é fruto de um sistema que impõe uma economia de exploração de recursos linear, extraindo-os do planeta com muito maior velocidade que ele consegue os repor, como afirma Latouche, indo ao encontro do que se falou sobre a exploração da Terra até aqui:

Nosso crescimento econômico excessivo choca-se com os limites da finitude da biosfera. A capacidade de regeneração da Terra já não consegue acompanhar a demanda: o homem transforma os recursos em resíduos mais rápido do que a natureza consegue transformar esses resíduos em novos recursos (LATOUCHE, 2009, p. 27).

O atual estágio de exploração da Terra está ultrapassando os seus limites. Não são conhecidos quais são estes limites, mas, como afirma Tim Jackson, "sabemos o bastante para estarmos absolutamente certos de que o nível atual de atividade econômica está destruindo a integridade ecológica e o ecossistema" (JACKSON, 2013, p. 59). Não enxergar estes limites naturais que o planeta possui é condenar as próximas gerações a muitas faltas, até mesmo para atender suas necessidades essenciais.

O vídeo intitulado "História das Coisas", disponível em site de busca de vídeos (Youtube), demonstra de uma forma simples e objetiva como o processo de produção capitalista interfere no meio ambiente, explorando a mão de obra e as necessidades de consumo do ser humano, que, em um processo complexo de devastação ambiental, poluição e produção de lixo, cria um sistema aparentemente funcional, mas que se analisado de forma detalhada mostra sua condição falha e prejudicial à humanidade e ao meio ambiente.

O processo de produção e consumo é chamado, neste caso, de "economia de materiais", o qual é composto pelas fases de extração, produção, distribuição, consumo e tratamento de lixo. Tudo acontece aparentemente de maneira natural e saudável, porém trata-se de um sistema em crise, pois é um sistema linear, que não funciona em um planeta finito. Integrado ao mundo, à sociedade e ao meio ambiente, encontra limites, que vêm sendo ultrapassados, prejudicando o bem-estar das pessoas e do planeta.

\footnotetext{
Conforme Luiz Marques Filho (2016), há cinco extinções anteriores, a primeira há 440 milhões de anos, a segunda há 365 milhões de anos, a terceira há 251 milhões de anos, a quarta há 210 milhões de anos a quinta há 65 milhões de anos. Está abrindo a era Cenozoica, que vivemos hoje, também chamada de Era dos Mamíferos.
} 
No momento da extração, o que realmente acontece é a constante e interminável exploração de recursos naturais. Em outras palavras, o extermínio do planeta, que vem tendo suas fontes naturais sendo esgotadas, animais extintos, águas contaminadas e poluição do ar constantes. Este processo de extração é insustentável tanto quando se refere à quantidade quanto à interferência tóxica nos recursos naturais.

A segunda fase é a produção, na qual os processos químicos existentes produzem constantemente toxinas, prejudicando a saúde dos seres humanos e de todo o meio ambiente. Afeta trabalhadores e consumidores, que entram em contato com toxinas o tempo todo, produzindo ou consumindo qualquer produto. Na fase de distribuição, é preciso vender tudo que foi produzido com as toxinas geradas para o máximo de pessoas possível. Ao encontro disto está o consumo, que acabou virando a identidade do ser humano: consumidor. Os indivíduos mantêm as mercadorias circulando o tempo todo, consumindo mais e mais, desnecessariamente para suas vidas e bem-estar, mas necessariamente para a manutenção do sistema capitalista.

A consequência disso é a produção interminável de lixo tóxico, que volta para o ambiente, poluindo mais ainda o planeta. A grande maioria - cerca de $90 \%$ - dos produtos consumidos viram lixo em menos de seis meses, o que obviamente se torna insustentável e extremamente prejudicial ao meio ambiente. É desta forma que age o sistema capitalista, com uma estrutura linear de exploração do meio ambiente, mão de obra e necessidades criadas pelos seres humanos, estes que fazem parte de uma engrenagem que produz e consome ao mesmo tempo, insaciavelmente, tornando insustentável o modelo atual de vida no planeta, gerando a crise ambiental atual e a crise de identidade dos indivíduos e das sociedades existentes.

Em relação à possibilidade de uma sustentabilidade ambiental conciliada ao sistema capitalista, José Eli da Veiga (2005) aponta para o que considera até aqui muitas teorias e discursos falhos, no que se refere a manter um desenvolvimento da economia ao mesmo tempo em que se caminha para uma sustentabilidade ambiental do planeta. Segundo ele, "a hipotética conciliação entre o crescimento econômico moderno e a conservação da natureza não é algo que possa ocorrer no curto prazo, e muito menos de forma isolada, em certas atividades, ou locais específicos." (VEIGA, 2005, p. 113). Para tal compreensão, quando se fala em desenvolvimento sustentável, é preciso separar os dois termos e compreendê-los de uma melhor maneira, para só então conciliá-los.

O termo desenvolvimento geralmente é analisado sob o ponto de vista econômico, mas ele não é um fruto exclusivo das relações de mercado. "Os mercados são tão somente uma entre as várias instituições que participam do processo de desenvolvimento" (VEIGA, 2005, p. 80). O desenvolvimento é relacionado principalmente às pessoas, nas suas individualidades e na coletividade, tem a ver, "primeiro e acima de tudo, com a possibilidade de as pessoas viverem o tipo de vida que escolheram, e com a provisão dos instrumentos e das oportunidades para fazerem as suas escolhas" (VEIGA, 2005, p. 81). O desenvolvimento, portanto, tem a ver com a cidadania, a democracia e os direitos dos indivíduos, assim como o atendimento de suas necessidades materiais, intelectuais e culturais e a busca de sua felicidade. Desenvolver-se é característica vital do ser humano, e obviamente que não é apenas o desenvolvimento econômico que desencadeia sua vitalidade.

O desenvolvimento pode permitir que cada indivíduo revele suas capacidades, seus talentos e sua imaginação na busca da auto-realização e da felicidade, mediante esforços coletivos e individuais, combinação de trabalho autônomo e de tempo gasto em atividades não econômicas.[...] Maneiras viáveis de produzir modos de vida não podem depender de esforços excessivos e extenuantes por parte de seus produtores, de empregos mal remunerados exercidos em condições insalubres, da prestação inadequada de serviços públicos e de padrões subumanos de moradia (VEIGA, 2005, p. 80).

Já a sustentabilidade precisa ser vista de maneira mais ampla, não apenas com um olhar ambiental, ou considerando sua degradação em razão do consumo excessivo de recursos por parte do sistema capitalista. A sustentabilidade precisa ser vista como uma agregação de valores sociais, econômicos, culturais, e obviamente ambientais. É preciso considerar também a territorialidade, os valores culturais de cada sociedade, tendo um ponto de vista global e outro ponto de vista local. Não há uma receita única para esta construção, mas várias interpretações e caminhos a serem seguidos concomitantemente, encontrando uma harmonização nas ações de forma que a sustentabilidade ambiental seja alcançada de forma eficaz, ampla, com um foco tanto para o local quanto para o global. 
Alcançar estes objetivos trata-se do grande desafio da humanidade. Compreender o atual estágio de degradação ambiental e suas consequências é muito difícil. Encontrar um caminho ideal para o alcance de uma sustentabilidade ambiental real torna-se mais difícil ainda quando as análises e propostas existentes parecem tão distantes de serem palpáveis ou visíveis. Como afirma Veiga, "as diversas versões sobre o desenvolvimento sustentável parecem estar muito longe de delinear, de fato, o surgimento dessa nova utopia" (2005, p. 208). Fato é que compreender melhor o que significa o "desenvolvimento sustentável" é o primeiro passo para encontrá-lo.

Se existem, contudo, pontos de vista mais pessimistas, como o visto anteriormente, também existem pontos de vista que enxergam alternativas para uma mudança de rumo da humanidade e sua relação com o meio ambiente. $O$ debate ambiental é muito recente, porém vem avançando rapidamente e tomando força no que respeita à efetividade das ações realizadas para a amenização dos impactos ecológicos da exploração feita pelo sistema capitalista. É possível enxergar cenários mais otimistas, de possibilidades de uma sustentabilidade ambiental em meio ao modo de vida consumista da humanidade.

Enxergar a possibilidade de uma proposta de racionalidade ambiental entrelaçada à economia capitalista é um ponto vista otimista. Trata-se de uma reconstrução da economia e nas bases de produção de bens materiais, respeitando a capacidade do planeta de gerir recursos. Uma árdua tarefa, mas possível de ser construída, segundo Leff (2010), que acredita ser necessária uma ruptura na economia para que ela tome um novo rumo, de sustentabilidade e racionalidade ambiental.

A construção de uma economia fundada em princípios de racionalidade ambiental significa assumir o desafio que implica a reconstrução do paradigma da economia. Não bastam os esforços para conciliar a racionalidade econômica e seu complexo campo de externalidades com pequenas acomodações como as propostas na época pré-moderna pela cosmovisão ptolemaica para ajustar os ciclos dos movimentos das esferas celestes de modo a manter a visão teológica do mundo como centro do universo. Só quando se produziu uma ruptura epistemológica que colocou a Terra em seu lugar é que foi possível mudar as relações de poder entre a Igreja, o Estado e a cidadania. A economia precisa de um descentramento, de uma ruptura e uma refundamentação semelhantes, que acabem com a supereconomização do mundo, com a centralidade e o domínio da razão econômica sobre as outras formas de racionalidade e formas de ser no mundo. Não é fácil fazê-lo, mas será a única maneira de passar à sustentabilidade (LEFF, 2010, p. 31).

A sustentabilidade é a única possibilidade de um futuro, segundo Leff (2010), constituindo ela uma maneira de repensar a produção e a economia, "de abrir o fluxo do tempo a partir da reconfiguração das identidades, rompendo o cerco do mundo e o fechamento da história impostos pela globalização econômica" (LEFF, 2010, p. 31). A crise ambiental está motivando esta nova forma de repensar o mercado, trazendo à racionalidade econômica um processo de total reformulação, considerando princípios que regem a vida sustentável no planeta. Isto resulta na legitimação de novos valores, direitos e critérios para as decisões a serem tomadas na coletividade e na individualidade. A racionalidade ambiental fará com que seja necessário um novo contrato social, no qual a sociedade precisa aprender a viver sob os valores da sustentabilidade e da continuidade da biodiversidade e da espécie humana no planeta Terra.

Leff igualmente propõe que o discurso do desenvolvimento sustentável busca solidariedade internacional e consenso das nações quanto aos problemas globais. São necessárias algumas ações para que seja alcançada a sustentabilidade, como aliar a tecnologia à busca de regeneração dos recursos naturais e de equilíbrio ecológico, aliando assim sustentabilidade e crescimento econômico, além de incluir a busca de uma racionalidade ambiental nas lutas sociais, construindo assim um "novo paradigma produtivo, a produção de novos conhecimentos científicos, o resgate dos saberes e das práticas tradicionais para descobrir novos usos potenciais dos recursos naturais" (LEFF, 2009, p. 233), organizando a produção de maneira sustentável e atendendo às necessidades da sociedade, diminuindo desigualdades, respeitando a cultura de cada nação.

A humanidade precisa encontrar prosperidade sem necessitar "crescer" infinitamente. Um dos grandes discursos do capitalismo é defender a necessidade de um constante crescimento. E o termo crescimento refere-se a tudo. A linearidade do sistema não prevê estagnação nem estabilização. Sempre se quer mais e se explora mais. O resultado disso é a crise ambiental já constatada neste trabalho. Alguns autores defendem uma ideia de decrescimento, que seria um caminho para a sustentabilidade ambiental do planeta. 
É possível, no entanto, falar em decrescimento em meio ao atual sistema capitalista? Seria este projeto apenas uma "utopia", como afirma Latouche? Ou, como o autor completa, "Longe de se refugiar no irreal, tenta explorar as possibilidades objetivas de sua aplicação" (LATOUCHE, 2009, p. 40). O decrescimento pode ser um projeto viável, também se tornando uma alternativa e um novo caminho de sustentabilidade ambiental.

A revolução exigida para a construção de uma sociedade autônoma de decrescimento pode ser representada pela articulação sistemática e ambiciosa de oito mudanças interdependentes que se reforçam mutuamente. Podemos sintetizar o conjunto delas num "círculo vicioso" de oito "erres": reavaliar, reconceituar, reestruturar, redistribuir, relocalizar, reduzir, reutilizar, reciclar. Esses oito objetivos interdependentes são capazes de desencadear um processo de decrescimento sereno, convivial e sustentável (LATOUCHE, 2009, p. 42).

Da mesma forma, Tim Jackson sugere, como o próprio título de sua obra, uma "prosperidade sem crescimento", entendendo que a prosperidade pode ser alcançada sob um ponto de vista de "florescimento", mas um florescimento menos materialista, que abandone a crucial necessidade de crescimento linear econômico. Assim, tratar-se-ia de uma prosperidade duradoura, ou seja, sustentável. Prosperidade esta que, de fato, seria sinônimo de felicidade e bem-viver.

O progresso depende crucialmente da construção de alternativas críveis. A tarefa é criar capacitações reais para que as pessoas floresçam de modos menos materialistas. Em uma escala social, isso significa investir nessas capacidades: física, financeira e emocionalmente. Em particular, precisamos revitalizar a noção dos bens públicos. Renovar nossa sensação de espaço público, de instituições públicas, de um propósito comum. De investir dinheiro e tempo em metas, ativos e infraestrutura partilhados (JACKSON, 2013, p. 215).

A questão não está no abandono do consumo, pois este também é vital para o ser humano, mas necessita-se indagar profundamente as bases do materialismo em sua condição de essencialidade. Em meio ao sistema capitalista atual, torna-se impossível buscar tal mudança de paradigma, porém pode tornar-se totalmente possível uma releitura da importância dos bens materiais na vida das pessoas, para que deixem de ser tão fundamentais. Este seria um primeiro grande passo para uma prosperidade - ou uma felicidade - sustentável.

\section{CONSIDERAÇÕES FINAIS}

Esta pesquisa não apresenta respostas definitivas sobre a crise ambiental e as possibilidades de futuro da espécie humana; também não constitui um manual para sociedades sustentáveis, uma receita ou um conceito acabado sobre o tema. Ao contrário, indaga-se sobre as bases da sociedade de consumo e tal comportamento como opção de felicidade e realização humana, confrontadas com os elementos causadores da crise ambiental e a ameaça de colapso ecológico, que paira sobre nossas cabeças em decorrência das escolhas feitas pela sociedade moderna, para o desenvolvimento.

O caminho da humanidade até aqui representa grandes conquistas, traduzidas na qualidade e na expectativa de vida, nos avanços tecnológicos, no acesso ao conforto, ainda que distribuídas de forma desigual nos diferentes continentes. Muitos pontos de vista sobre a humanidade, entretanto, foram modificados e novas dúvidas emergem, restando brechas sociais e econômicas revelando grande iniquidade no contexto global. $\mathrm{E}$, nas últimas décadas, as externalidades deste processo apresentam impactos ambientais com os quais não será possível prosseguir.

Nesse sentido, a perspectiva da modernidade, como época de grandes inventos e inovações tecnológicas, gerou uma profusão de possibilidade de consumo, sem, entretanto, atentar para a dimensão da finitude e dos limites do planeta. A percepção de que o ambiente tem limites na capacidade de ofertar riquezas é incompatível com a prática de busca por níveis ilimitados de consumo. Por seu turno, o extrativismo resultante da conversão da natureza em commodity, está na base das preocupantes mudanças climáticas, expondo as incompatibilidades entre limites da natureza e não limites ao consumo. As novas análises que pretendem estabelecer limites ao crescimento denotam a geração de necessidades artificialmente produzidas, com a finalidade única de promover ampliação dos níveis de consumo.

O mercantilismo e a industrialização do mundo globalizado desenvolveram uma nova maneira de viver, que não precisa ser malvista em todas as situações, mas que necessita ser mudada em muitas delas. A condi- 


\section{Direito自 \\ Debate}

SOCIEDADE DE CONSUMO E A (IN)SUSTENTABILIDADE DO SISTEMA CAPITALISTA VIGENTE

Daniel Rubens Cenci - Willian Matheus Heineck

ção de insustentabilidade ambiental do sistema capitalista fará com que o homem busque uma nova maneira de viver. Caso contrário, estará impossibilitada sua existência humana na Terra.

Cabe então indagar se é possível saciar as necessidades do homem absolutamente? Tal questão permanece em aberto, porquanto a ideia de decrescimento não dialoga com os projetos de vida na atualidade.

O homem carrega sua essência biológica, natural, ancestral, mas esta mescla-se com o que é construído no seu mundo civilizado. O ser humano é um complexo de construção histórica e biológica. Atender às suas necessidades como um todo é impossível. Assim sendo, é preciso buscar um equilíbrio nas escolhas realizadas, pois só assim será possível aproximar-se de um bem-estar no presente e que se prolonga, pela responsabilidade e solidariedade estendidas, às futuras gerações.

Resta, pois, encontrar novos caminhos para a vida sustentável, que não coloquem o consumo como o objetivo essencial do ser, mas como apenas uma condição de sobrevivência e conforto.

\section{REFERÊNCIAS}

BOFF, Leonardo. Sustentabilidade: o que é - o que não é. 1. ed. Petrópolis: Editora Vozes, 2012.

CAPRA, Fritjof. A visão sistêmica da vida: uma concepção unificada e suas implicações filosóficas, políticas, sociais e econômicas. Trad. Mayra Teruya Eichemberg. São Paulo: Editora Cultrix, 2014.

JACKSON, Tim. Prosperidades sem crescimento: vida boa em um planeta finito. Trad. José Eduardo Mendonça. São Paulo: Editora Planeta Sustentável, 2013.

JAMIESON, Dale. Ética e meio ambiente - uma introdução. 1. ed. São Paulo: Editora Senac, 2010.

LATOUCHE, Serge. Pequeno tratado do decrescimento sereno. Trad. Claudia Berliner. São Paulo: Editora WMF Martins Fontes, 2009.

LEFF, Enrique. Ecologia, capital e cultura: a territorialização da racionalidade ambiental. Trad. Jorge E. Silva. Petrópolis: Editora Vozes, 2009.

LEFF, Enrique. Discursos sustentáveis. Trad. Silvana Cobucci Leite. São Paulo: Editora Cortez, 2010.

MARQUES FILHO, Luiz César. Capitalismo e colapso ambiental. 2. ed. Campinas: Editora Unicamp, 2016.

SEMPERE, Joaquin. Mejor con menos: necesidades, explosión consumista y crisis ecológica. Barcelona, Espanha: Editora Crítica, 2009.

VEIGA, José Eli da. Desenvolvimento sustentável: o desafio do século XXI. Rio de Janeiro: Editora Garamond, 2005.

YOUTUBE. A história das coisas. Site de busca de vídeos. Acesso em: https://www.youtube.com/watch?v=7qFiGMSnNjw. Acesso em: 30 jan. 2018. 